\title{
N145 Latency
}

National Cancer Institute

\section{Source}

National Cancer Institute. N145 Latency. NCI Thesaurus. Code C117886.

An assessment of the latency of the N145 or N2 wave of the visual evoked potential assessment waveform. 